\section{What Is It You Want From Us?}

Al Soeldner, Oregon State University

I manage a university service electron microscope facility which provides transmission, scanning transmission, and scanning electron microscopy, each with $X$-ray energy spectrometry, as well as feature analysis, specimen preparation, and training services. Clients of the facility do basic and applied research in

- human, animal, and plant health, pharmacy, and bioengineering;

- air, water, and soil ecology, pollution, and resource development and conservation;

- forest pathology, productivity, and development and performance of wood products;

- foods and nutrition:

- engineering, advanced metallic, ceramic, glass, and polymeric materials development, failure analysis, and tribology

- botany, entomology, microbiology, zoology, chemistry, geology, and physics.

Clients bring a need and some expectations to a service facility like this. Often their needs and expectations are vague, poorly defined, and expressed in inaccurate and imprecise terms. Nevertheless, clients have "pictures" in their heads about what they'll see or learn, and what image, spectrum or data table will constitute their "result"

As service provider managers, we should seek to understand our client's possible ignorance, as well as their needs and expectations, in the context of their mental pictures and the eventual tangible evidence anticipated from work presented to us. It is useful to understand these things as quickly as possible after a client begins speaking about their work. Failure to clearly define a client's exact needs and expectations and their mental conceptualizations of anticipated results too frequently bring about situations which waste time, effort, and/or specimens, increase cost or reduce income, and lead to client dissatisfaction or ill-will.

Two fundamental questions to ask toward achieving a good understanding of a client's needs, expectations, and the mental pictures and tangible evidence they anticipate are: (1) what specific information do you want, and (2) what do you see as the most useful way to have this information reported?

Initially we need a client to describe those expected images or results they are carrying in their dreams and their ideas about ideal ways these images or results would be given to them. At this point it makes little difference if the answers we receive make good scientific or technical sense, nor does it matter in the least whether the materials presented for examination conform to or refute the client's expectations.

A client may not be knowledgeable or technically conversant enough to offer much initial information. That is significant in itself. Acquiring helpful

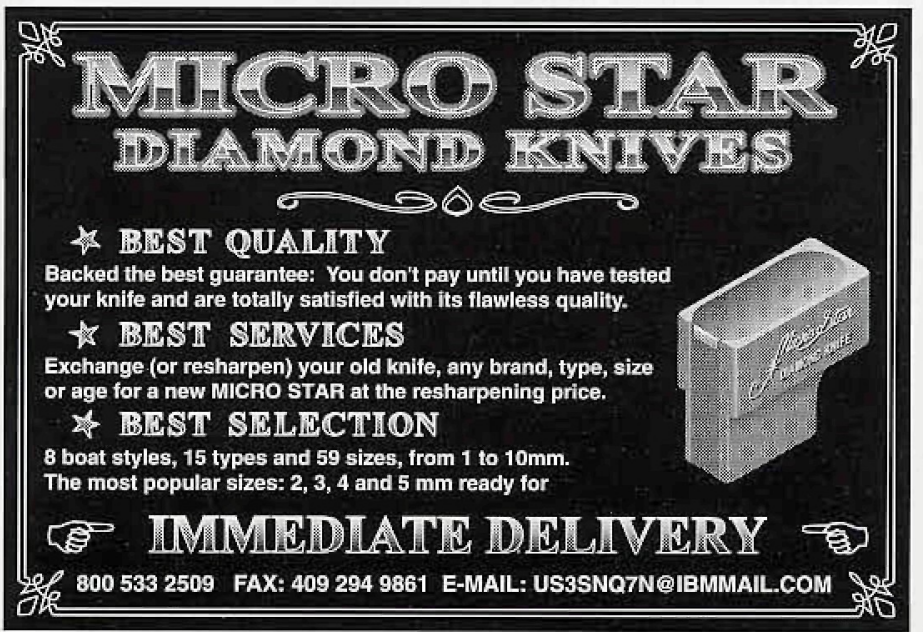

answers to the questions must be both an interactive and iterative process. From the responses obtained, details about methods, accuracy and precision, time investments, costs and so forth can be exchanged. More focused questions can then be posed which should lead both the client and service provider toward a clear mutual consensus about the information to be sought and the format for reporting the results, before work is initiated.

Information available through microscopy, spectrometry, or the two in combination might include

- Structural appearance/documentation

- Damage/failure mode analysis;

- Presence/absence/type of contamination/effect

- Sample consistency/variation;

- Changes to specimen over time/process effects;

- Generalized qualitative/quantitative element analysis;

- Specific element identification/yes-no information;

- Qualitative/quantitative chemistry relative to structure

- Spatial distribution of elements:

- Ratio between elements in same or different samples:

- Qualitative/quantitative data between unknown and reference samples

Examples of data formats might include

- Micrographs (random area, magnification series, montages, stereoscopic);

- Feature size/shape statistics;

- Line profiles of element concentrations;

- Element distribution maps:

- Color coded maps/images;

- Spectral plots;

- Tables (elements, energy, atomic or weight $\%$, etc.)

- In-depth technical reports.

Ultimately, our goals are to educate ourselves about clients needs and expectations while educating our clients about our service capabilities, options, and limitations. This two-directional education works to everyone's benefit. Basic decisions should be made in a fully informed and mutual way, as well as with an acceptance that a plan may need to change if unexpected things are found. Basic decisions might include:

- Nature of problem or question(s);

- Choice of method(s)

- Choice of sample(s)

- Purpose of analysis

- structural information

- chemical information

- temporal information

- descriptive information/documentation

- basic investigative research

- study to support research finding/supposition

- answer technical question, solve technical problem

- failure analysis

- Spatial resolution required (point, edge, area, depth)

- Chemical resolution required

- element coverage

- specificity

- detection limit

- ease/accuracy in qualitative/quantitative data

- Temporal resolution required

- How to present data

- Sample through-put requirements, limitations

- Time considerations (data return time vs. data production time requirements)

- Convenience of the analysis required

- Best method(s), alternatives

- cost

Hence, it's helpful to ask: what is it you want from us? What specific information do you expect, and what do you see as a useful way to have this information reported? 


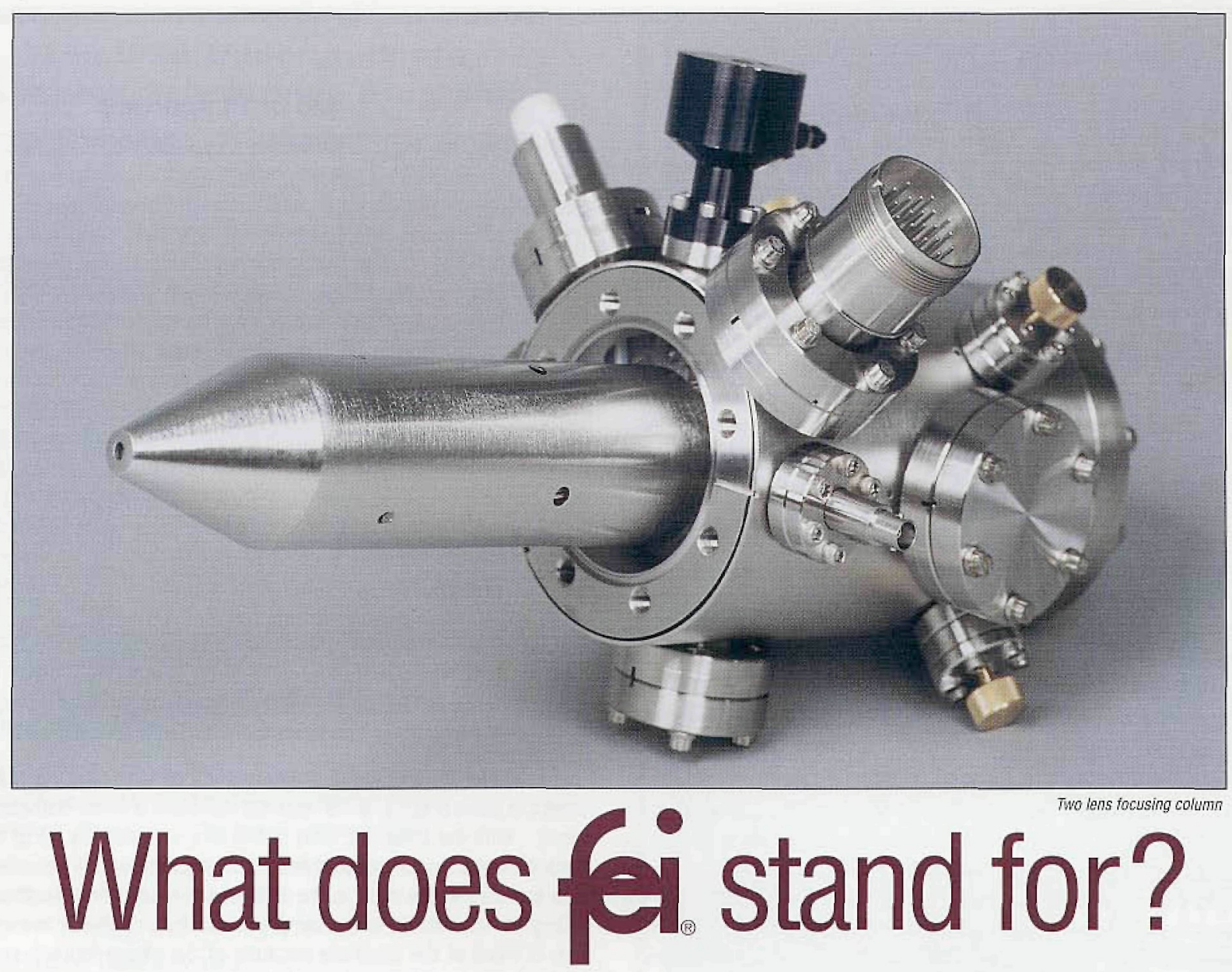

Our compact, UHV, field emission columns are used by researchers world wide. Innovative electrostatic optics and dedicated electronics allow you to integrate a high current density electron or ion column into most vacuum systems. FEl also supplies researchers with other specialized products...

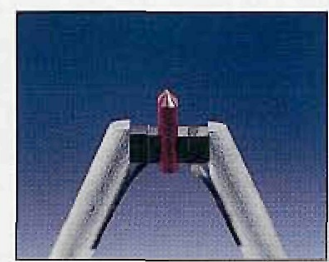

\section{$\mathrm{LaB}_{6}$ an $\mathrm{CeB}_{6}$ Cathodes}

FEl's Mini-Vogel Mount, the first universally compatible long-life, high-stability LaB6 cathode, provides excellent performance and the best cost-per-use value for installation into your EM systems.

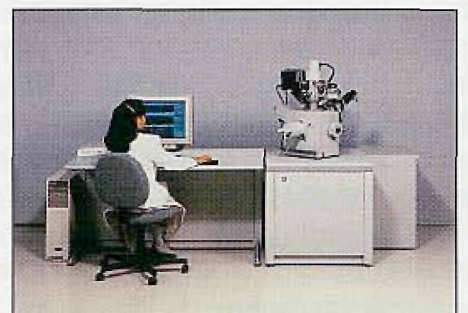

\section{FIB Workstations}

Focused ion beam micromilling workstations range from the $8^{\prime \prime}$-wafer compatible model to the economical 2 " small sample model ideal for semiconductor, biological, TEM, and MEMS specimens.

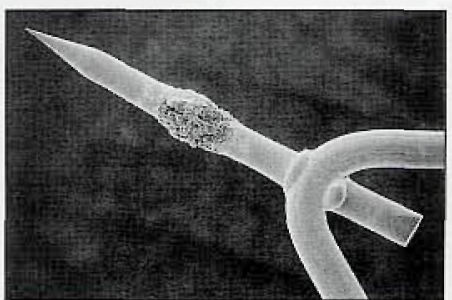

Field Emission Cathodes

FEI supplies Schottky field emitters to EM manufacturers worldwide. Schottky emission's high current intensity has established it as the preferred electron source for high resolution SEM, TEM, Auger, ESCA, $E D X$, and lithography.

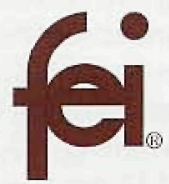

FEI Company

7451 NE Evergreen Parkway

Hillsboro, OR 97124-5830

(503) 640-7500 Fax (503) 640-7509

email:rsk@feico.com

Now, when you think of FEI, you'll know we are the Specialists in Field Electron and Ion Technology. 